\title{
VOZES DOCENTES: \\ ANÁLISE DE REFLEXÕES DE PROFESSORES DE CIÊNCIAS SOBRE SUA VIVÊNCIA PROFISSIONAL
}

\section{Maria Cristina Doglio Behrsin*}

RESUMO: O presente texto traz algumas reflexões feitas durante a realização de uma pesquisa sobre formação de professores, cujo objeto de estudo se estabeleceu em torno de elementos da caminhada docente de seis professores de Ciências. A citada pesquisa teve como ponto de confluência das histórias de vida profissional desses professores, a sua participação em um curso de Pós-Graduação em Ensino de Ciências. A partir dos relatos, buscou-se identificar aproximações e distanciamentos em suas percepções sobre a escola, a Educação e o trabalho docente, tecendo-se um diálogo entre os protagonistas da pesquisa e entre estes e diversos autores que tem investigado sobre as questões recorrentes em suas falas, objetivando, assim, trazer algumas contribuições para o debate.

Palavras-chave: Educação em Ciências; Formação de Professores de Ciências; História de Vida Profissional.

\section{TEACHING VOICES: ANALYSIS OF THE REFLECTIONS OF SCIENCE TEACHERS ABOUT THEIR PROFESSIONAL EXPERIENCE}

ABSTRACT: The present text shows some reflections made during the accomplishment of a research regarding the graduation of teachers, whose object of studies was established around the elements of the teaching journey of six Science teachers. The mentioned research had as a point of confluence the histories of the professional life of these teachers, its participation in a course of Post Graduation in Science Teaching. From the reports onwards, one sought to identify the approximations and distances in its perceptions about the school, the Education and the work of teaching, establishing a dialogue among the protagonists of the research and among the several authors who examined the questions recurrent of these speeches, intending, therefore, to give some contributions to the discussion.

Keywords: Education in Science; Graduation of Science Teachers; History of the Professional Life. 


\section{INTRODUÇÃO}

O presente artigo se propõe a apresentar algumas reflexões feitas durante a realização de uma pesquisa relacionada à formação de professores tomando como referencial a perspectiva de que o desenvolvimento profissional docente se dá de modo continuum (MARCELO GARCIA 1992, p. 54), ao longo toda a vida.

O ponto de partida para o nosso estudo foi a participação de seis professores de Ciências dos $3^{\circ}$ e $4^{\circ}$ ciclos do Ensino Fundamental no curso de PósGraduação em Ensino de Ciências oferecido pela Universidade Federal Fluminense.

O curso representou o espaço em que ocorreu o entrelaçamento dos percursos de nossos sujeitos - professores que se tornaram alunos novamente, buscando a renovação de suas práticas profissionais cotidianas e mesmo de suas ideias a respeito do ensino, de seus alunos, das Ciências, da profissão, da vida... O curso representou, também, uma referência no tempo: é a partir dele que olhamos para a trajetória desses professores. Procuramos captar como os professores analisavam o caminho profissional já percorrido tendo como base a sua participação no curso, a importância creditavam ao seu envolvimento neste programa de formação continuada para a sua ação docente atual e as que contribuições acreditavam ter recebido para a formulação de perspectivas futuras.

Avaliamos que, ao trazer suas experiências cotidianas para serem discutidas em um programa de formação continuada, o professor tem oportunidade de revisitar a sua própria prática. Assim, a atividade realizada pode contribuir com um elemento "decodificador" do trabalho docente (SELLES, 2000). Dentro deste contexto, o encontro entre as vivências escolares e as formulações teóricas ganha um sentido potencializado, favorecendo, assim, o desenvolvimento de uma atitude reflexiva. É justamente isso que queremos evidenciar aqui.

Para construir nossa pesquisa, buscamos os professores-alunos entre os participantes do curso em cinco anos subssequentes (de 1995 a 1999), sendo, pelo menos, um aluno de cada ano. Um aspecto importante em nossa seleção era que tais professores atuassem (ou tivessem atuado) no ensino de Ciências da Rede Pública de Educação e que mantivessem contato com a universidade, mesmo após a conclusão do curso. Realizamos, com os mesmos, entrevistas semiestruturadas que complementaram nossa pesquisa, procedemos análise documental do curso e entrevistas semiestruturadas com duas professoras coordenadoras de tal iniciativa de formação continuada.

Ao realizarmos as entrevistas com os professores-alunos levamos em consideração o que recomenda Nias (apud SANTAELLA, 1998, p. 268): "para compreender a conduta profissional do professor de uma forma adequada é necessário realizar uma análise profunda de como se vêem os professores a si mesmos ao longo de sua carreira profissional". Nesta mesma perspectiva, Santaella (op. cit.) afirma que a maneira com que os professores vêem a si no exercício profissional pode ser extremamente 
importante para o seu desenvolvimento, uma vez que tais impressões estão carregadas de sentidos próprios e teorias subjetivas de como ser professor.

Com este propósito, tínhamos em mente as intenções proferidas por Fontoura:

\footnotetext{
"Nós queríamos fazer emergir o subjetivo, o qualitativo, o afetivo (...) valorizar as experiências de vida, profissionais ou não, os encontros, as solidões e os medos vividos num espaço e num tempo específicos" e concordamos com Huberman (1995, p. 58), de que: “... os nossos dados vêm das proposições dos indivíduos sobre os fatos e não dos fatos em si. É um estudo das percepções dos professores sobre o ciclo de vida profissional, um estudo das (suas) representações". (Fontoura, 1995, p. 179)
}

Temos a compreensão de que as entrevistas estão situadas no tempo, tendo sido realizadas após, ou durante a participação dos professores no curso de Pós-Graduação em Ensino de Ciências. Portanto, supomos que as ideias que os atores desta pesquisa apresentam, em suas falas expressam as reflexões feitas a partir do curso e se articulam com as experiências vividas por cada um deles. Ressaltamos, ainda, a provisoriedade que este momento encerra, uma vez que, depois de gravarmos as entrevistas, certamente, muitas vivências novas foram sendo acrescentadas a cada percurso docente.

\section{VOZES DOCENTES}

O recorte que estabelecemos aqui, do referido estudo, prioriza destacar as vozes dos professores entrevistados - Renata, Eduardo, Júlia, Isabel, Luís e Débora - nomes fictícios, procurando, assim preservar a identidade de cada um deles. Buscamos trazer à tona as reflexões que fazem sobre sua vivência no magistério, o que pensam sobre Educação, ensino, aprendizagem, sua profissão, a relação com seus pares, a construção da sua maneira de ser professor (NÓVOA, 1995).

Os relatos revelam um movimento reflexivo constante desses professores enquanto constroem sua experiência profissional - realizam, avaliam, reformulam - elaborando uma opinião bastante definida acerca de aspectos relacionados à Educação e com frequência, utilizam a sua própria experiência como referencial para a análise do contexto educacional, como um todo (TARDIF et alli, 1991).

A seguir, apresentamos alguns aspectos mencionados por eles: 


\section{OS PROFESSORES, AS ESCOLAS E A ESCOLA}

A imagem que os protagonistas deste trabalho constroem acerca da escola/Escola, Educação e profissão é constituída com base em sentimentos e valores e ganha forma nas associações que fazem a partir de suas vivências.

Além de relacionarem-se com um estabelecimento de ensino concreto - a escola em que dão aula, os professores, também, estão vinculados a uma entidade educacional mais ampla. Esta última, também, está presente nos relatos colhidos, ainda que por vezes pareça que lhes é longínqua, abstrata, enquanto que em outras, bastante próxima e controladora. De uma forma ou de outra, podemos identificar, ao longo das entrevistas, que os docentes se sentem fazendo parte de um mecanismo institucional.

Assim, ao mencionarem sobre a escola em que trabalhavam no momento da entrevista ou trabalharam anteriormente, falavam, também, da rede particular, municipal, estadual, do sistema educacional como um todo, de como viam e sentiam a Educação no país, conjugando entendimento e emoção.

Com frequência, essas duas instâncias educativas se confundem em suas falas e em vários momentos é nítido que estão descrevendo a escola específica em que lecionam mas, em diversas ocasiões, a palavra escola ganha uma conotação mais geral. Ao expressarem suas ideias, os entrevistados muitas vezes transitam entre um sentido e outro sem apresentarem um limite definido. A nosso ver, os diferentes sentidos atribuídos à escola, que vão da especificidade de suas vivências particularizadas às generalizações em torno do sistema educacional, representam tentativas de teorização - ainda que não sistematizada - a partir das experiências vividas.

Procuramos construir categorias que pudessem sintetizar as impressões e sensações que estes docentes experimentam em sua prática cotidiana na escola e na Escola. Para o presente texto, selecionamos algumas delas, que serão apresentadas a seguir:

\subsection{Trabalhar com prazer}

Uma característica marcante nas entrevistas analisadas é a forma carregada de emoção com que os nossos sujeitos falam de seu trabalho. Todos comentam entusiasmados sobre o que têm produzido com seus alunos, suas descobertas e realizações. Certamente, um ponto que une os entrevistados é o fato de gostarem do que fazem. Em meio a muitas dificuldades, constrangimentos burocráticos, projetos não realizados que causam frustrações, existe algo que os impulsiona para frente: gostam de dar aula, desejam produzir....

Codo e Gazzotti (1999, p. 49 et seq.) em sua análise sobre o trabalho docente, introduzem o tema "Trabalho e afetividade" afirmando que, ao se relacionar com o meio em que vive, o homem dá significado a este através de sua ação. Esta significação é a expressão de sua subjetividade. Desta forma, o trabalho como produção humana traz em si a 
"tensão entre a objetividade do mundo real e a subjetividade do indivíduo que o realiza". Isto significa que "todo trabalho envolve algum investimento afetivo por parte do trabalhador, quer seja na relação estabelecida com outros, quer mesmo na relação estabelecida com o produto do trabalho.” (CODO \& GAZZOTTI, 1999)

A possibilidade de expressão, em maior ou menor grau, da subjetividade e da afetividade está vinculada à dinâmica própria de cada tipo de trabalho. Codo e Gazzotti (ibid.) diferenciam a atividade docente das demais, argumentando que a relação afetiva não apenas está presente,como é também um pré-requisito indispensável para a sua própria concretização:

Em outras palavras, é um trabalho impossível de ser taylorizado, de se enquadrar em uma linha de montagem fordista, um trabalho que, ou leva em conta os vínculos afetivos com os alunos, com o produto, com as tarefas, ou simplesmente não se viabiliza.

Júlia sintetiza bem esta situação:

... nós estamos meio cansados de dar aquela aula tradicional, né? Nós vamos tentar manter o bom ânimo, para conseguir fazer uma coisa um pouquinho diferente, que não só motive os alunos, como também, nos motive. Porque a gente está meio cansado daquele ensino sempre igual.

A fala de Júlia deixa nítida a sua vontade de fazer um trabalho criativo e a sua aversão pela mesmice na Educação. Podemos perceber que este sentimento não é só em função dos alunos, mas por ela mesma. Júlia demonstra a intenção de desenvolver algo que lhe seja prazeroso, em contraste com a ideia de trabalho, apenas, como uma obrigação. As suas palavras, dentro do contexto da entrevista, revelam, também, que este movimento de não conformismo, de não acomodação, de não é só seu mas, também, dos outros colegas de equipe. $\mathrm{O}$ desejo de desenvolver atividades que os satisfaçam profissionalmente os impulsiona a realizar o novo, o diferente, mesmo em circunstâncias contrárias.

Débora também relaciona sua satisfação com a satisfação dos alunos. Em vários momentos da entrevista, essa professora descreve atividades que tem desenvolvido com seus alunos. Demonstra grande entusiasmo ao mencionar o que tem feito. Para ela, não basta que os alunos tenham um bom desempenho na matéria: é importante que eles aprendam com satisfação. Débora utiliza como critério para avaliar se a aprendizagem está sendo agradável para os alunos ou não, o fato dela mesma estar gostando da atividade e deseja que esta seja prazerosa, tanto para eles, quanto para ela mesma.

... trabalho muito com água. É uma coisa fácil e que eles visualizam muita coisa, agitação de moléculas; tem aquela experiência que você pega água em três temperaturas diferentes e dissolve anilina. Eles acham aquilo o máximo. (...) Então, são coisa bem rápidas, que chamem a atenção deles. Justamente, assim, porque eu gosto, eles gostam... 
A ênfase que nossos entrevistados dão ao desenvolvimento de atividades em sua prática que tenham, efetivamente, significado para eles, nos leva à afirmação de Tardif (2000, p. 15) de que ensinar é:

\begin{abstract}
...uma atividade intencional e profundamente subjetiva através da qual o professor se envolve em projetos que tem sentido para ele e em função da compreensão que ele tem de seu trabalho, de seus alunos etc. Ao entrar em interação com os alunos, o professor almeja atingir objetivos a partir de suas próprias perspectivas, expectativas, valores etc. Todavia, os alunos também são pessoas que possuem igualmente objetivos, intenções, expectativas. Uma aula é, por conseguinte, um processo de ajustamento, de imbricação e de transação entre as perspectivas recíprocas dos parceiros da interação. Em suma, o ensino é um trabalho personalizado, uma relação interpessoal. O 'saberensinar' não se refere a um conhecimento que pode dominar a ação, mas sim a um saber-fazer e a um saber- ser em harmonia com as características internas da situação. Por isso, a personalidade do professor - tudo o que ele é enquanto pessoa - constitui aqui o fator decisivo do ensino: o saber é incorporado à vivência do professor, confundindo-se, em última instância, com sua pessoa.
\end{abstract}

Corroborando com esta percepção expressa nas falas dos professores, temos a síntese, apresentada por Nóvoa com base em Nias (apud Nóvoa,1992, p. 25): "O professor é a pessoa. E uma parte importante da pessoa é o professor".

\title{
1.2. Liberdade na estrutura escolar
}

Os seis professores também manifestaram nas entrevistas a necessidade que sentem de terem liberdade no estabelecimento de ensino para poder dar asas à sua criatividade e desenvolver um trabalho que seja dinâmico e interessante a eles e aos alunos, além de uma estrutura básica para viabilizar as suas ideias.

As falas desses professores revelam que, em sua atividade docente, eles têm procurado estabelecer o equilíbrio entre essas duas necessidades fundamentais: liberdade e estrutura. No entanto, o equilíbrio desejado entre essas necessidades tem se mostrado bastante frágil em sua experiência cotidiana, pendendo, predominantemente, ora para um lado, ora para o outro. Além disso, liberdade e estrutura se apresentam, muitas vezes, como excludentes.

Ao comentarem a respeito dessas duas características: liberdade e estrutura, os entrevistados, de uma forma geral, contrastam escola particular e escola pública, identificando, ainda, diferenças entre escolas públicas da rede municipal e estadual.

Júlia, ao comparar escola pública com a escola particular, avalia que nesta última há uma exigência maior quanto a se trabalhar o conteúdo. Para ela, na primeira há mais liberdade - não se cobra muito do professor. O profissional que deseja desenvolver um trabalho inovador se sente mais livre, não existindo uma exigência quanto ao cumprimento de um programa preestabelecido: $\mathrm{Na}$ escola pública a gente tem mais liberdade, não é tão condicionado ao conteúdo. Na escola particular a gente é mais condicionado a trabalhar o conteúdo... 
Na continuação de sua fala, Júlia traça um paralelo entre rede pública e privada, avalia, ainda, que em alguns estabelecimentos particulares existem "melhores condições para trabalhar. ... na época em que eu trabalhava lá, tinha muito apoio para trabalhar a prática (...) então, era uma boa condição de trabalho, uma coisa que na escola pública a gente não consegue."

Renata faz menção à sua rápida experiência em estabelecimento particular de ensino (apenas seis meses), considerando de elite a escola em que trabalhou. Ao fazer esta classificação, Renata não se refere ao nível socioeconômico de seus alunos. O que ela destaca é o número de alunos dentro da sala de aula, o que, para ela, possibilita um trabalho de mais qualidade, favorecendo a realização de atividades práticas. Para Renata, o número excessivo de alunos presentes nas turmas nas escolas públicas, em geral, impede a utilização de uma metodologia semelhante à da escola particular em que trabalhou.

... [a escola particular] por ser uma escola pequena, era uma escola com a metodologia totalmente diferente, que não poderia jamais ser aplicada no município, porque era turma com dez alunos. Você trabalha mais a prática do que a teoria (...) a diferença é justamente com relação ao número de alunos que existem nas salas. Na escola pública trinta e cinco, na escola particular número de dez.

Eduardo avalia que na escola particular, em geral, há uma estrutura melhor, tanto no sentido material, como também com relação ao apoio pedagógico, mas lembra que em muitas escolas particulares não existe esse apoio pedagógico:

Dependendo da escola particular, você, realmente, percebe que, em algumas, você encontra uma preocupação maior com a questão pedagógica, uma estruturação maior, um acompanhamento pedagógico, uma coordenação pedagógica atuante (...) em outras (...) praticamente não existe uma coordenação pedagógica presente. As pessoas ficam muito jogadas...

Da mesma forma com que Eduardo conclui que nem sempre escola particular representa mais organização e mais estrutura de trabalho e apoio pedagógico, podemos identificar na fala de Luís e de Isabel menção ao apoio e consequente organização que encontraram na escola pública, principalmente por parte da direção.

Luís refere-se à escola municipal em que trabalhou, explicando como esta contribuiu para mudança no rumo de sua carreira: "... eu encontrei (...) uma direção, assim maravilhosa, competente, uma direção envolvida no trabalho ..."

Isabel, a partir de sua experiência em escola municipal, avalia: "No município é assim, né? Tem escolas que você tem uma direção que aí faz a escola ser mais dinâmica, tenta fazer um trabalho um pouco mais interessante..."

Luís contrasta, ainda, as escolas da rede municipal e da estadual e avalia que há maior organização na rede municipal: "o município é bem mais organizado, leva uma discussão mais à sério do que o estado”. 
Renata também identifica a falta de uma estrutura de trabalho mais organizada na escola estadual, ao comparar com o que experimentou no município:

Eu acho que, esses anos todos em que eu trabalhei no município, existe uma integração maior na escola, em todos os sentidos, tanto o aluno, quanto o professor, eles são mais cobrados e parece que as coisas funcionam melhor (...) Agora no ensino supletivo, como é uma coisa estadual, é totalmente solto, cada um faz o que quer, da maneira que quiser. Vai muito do seu senso de responsabilidade, da sua consciência como profissional.

Para Renata, a falta de cobrança presente nas escolas estaduais favorece o descompromisso de alguns colegas. Avaliação semelhante a que é apresentada por Eduardo. Ao valorizar a liberdade que experimenta na escola pública, faz a seguinte ressalva: "Da mesma forma, os professores, também, que são mais desinteressados, eles acabam tendo, também, espaço..."

Os relatos de nossos entrevistados apontam diversas faces da questão: é fundamental para o docente poder trabalhar de maneira criativa, se sentir livre para, junto com sua turma, poder produzir. Desta forma, ao comparar rede pública e privada, alguns deles destacam que, não havendo cobrança exagerada, principalmente nas escolas estaduais quanto ao cumprimento de um programa preestabelecido, o trabalho flui melhor. No entanto, esta situação também facilita aqueles que nada querem.

Da mesma forma, tais professores também manifestam a necessidade de se sentirem respaldados por uma estrutura de trabalho na escola que possa garantir a viabilidade de seus projetos. No entanto, nas escolas em que há uma organização maior, em geral, nas do sistema privado, com frequência há também uma cobrança mais rígida quanto ao cumprimento de programas e regras não planejadas ou intencionadas pelo professor.

Tais ambiguidades são identificadas e vividas intensamente pelos seis professores. Justamente nos estabelecimentos em que parece haver uma liberdade maior, deparam-se com descaso e desinteresse que, certamente, petrificam as tentativas de voos pedagógicos mais ousados. Por outro lado, um estabelecimento de ensino com uma estrutura mais organizada pode significar o respaldo de que os docentes necessitam para realizar seus projetos, mas correm o risco de se verem envolvidos com burocracias sufocantes e cobranças excessivas.

Foutoura (1992, p. 176) expressa bem os dilemas vividos por esses professores e tantos outros ao vivenciarem a necessidade de liberdade para trabalhar, mas não a encontrarem de maneira efetiva:

Exercer sua liberdade e responder às necessidades da sociedade dá lugar a inúmeras ambivalências, pois que, seja qual for o grau de autonomia, pessoal e ideológica do professor, essa autonomia sempre se inscreverá num quadro de estruturas e de normas políticas e culturais. Na verdade o professor nunca está sozinho, nem mesmo na classe, com seus alunos. As exigências da instituição, a posição dos projetos indivi- 
duais, a pressão social, as solicitações do exterior inscrevem-se cada vez mais no sistema relacional professor/aluno e influenciam cada vez mais o ato pedagógico. (...) A situação é extremamente complexa e acaba por levar o professor à construção de uma identidade profissional própria forjada no encontro em si mesmo de lógicas contraditórias e de referentes nem sempre compatíveis.

\subsection{Descompromisso e burocracia estagnadora}

Ao analisarem o funcionamento da escola em que trabalham, os entrevistados identificam, ainda, a presença de uma estrutura burocrática rígida, até mesmo na escola pública que, no lugar de contribuir para que ocorra uma maior agilidade das atividades, torna-se estagnadora, dificultando a ação daqueles que querem produzir.

A narrativa de Júlia expressa bem esta situação ao descrever uma experiência vivida por ela em uma escola estadual. Júlia menciona o empenho da equipe de Ciências e Biologia em desenvolver um projeto conjunto e a decepção resultante das dificuldades impostas pela organização escolar:

... fiquei bastante frustrada no primeiro dia de aula quando cheguei lá e vi que não ia ter contato, um dia só junto com os meus colegas de equipe (...) um dia por semana no recreio, que era quando a gente poderia se reunir, não dá para combinar nada.

Linhares (1996) associa burocratização e a racionalidade técnica, presente no sistema escolar que, por meio de decisões mecânicas, busca a exequibilidade de planos cujo fim exclusivo da ação é o funcionamento do próprio sistema. Isto faz com que as atividades administrativas sejam consideradas mais importantes do que as pedagógicas em uma escola. O relato de Júlia evidencia bem tal característica. Uma vez conseguindo-se organizar a grade de horários sem deixar furos ou lacunas, acredita-se que a responsabilidade educacional do estabelecimento terminou, não importando se os professores da área de Ciências ou de outra área não terão horário disponível para se reunir. Isto não é considerado prioritário.

Linhares (ibid.) associa, também, burocratização e hiperespecialização, que traz uma fragmentação das atividades, distanciando os atores da escola de seus pares e alienando-os de uma percepção mais ampla do processo educacional. Desta forma, através de constrangimentos burocráticos, os professores deixam de ser vistos como "pessoas" e passam a ser assumidos como "espaços" a serem preenchidos nas grades de horário.

Linhares (ibid., p. 107) completa seu raciocínio, citando Gandini (1985), que afirma: "A divisão do trabalho, a consequente burocratização e o fato de alguns indivíduos se tornarem executores de decisões tomadas por outrem, induz à irresponsabilidade quanto ao próprio trabalho."

A análise de Gandini vem trazer luz a uma inquietação presente nas falas dos entrevistados quanto ao descompromisso de vários colegas para com a 
Educação. A burocratização do trabalho docente confina os professores ao exercício de atividades que carregam, em si, o peso de serem ao mesmo tempo, urgentes e rotinizantes, praticamente inviabilizando a oportunidade de se desenvolver no ambiente escolar algo que seja relevante para professores e alunos. Isto, com o tempo, gera apatia e desinteresse, tanto por parte de docentes quanto discentes, e leva-os a vivenciarem o cotidiano escolar sem se darem conta do que significa ou poderia significar tal espaço para eles.

Esta situação nos faz refletir sobre a tênue fronteira existente entre institucionalização e burocratização. Os entrevistados comentam sobre a importância de uma organização escolar que lhes forneça o respaldo necessário para o desenvolvimento do trabalho docente e, no entanto, uma estrutura excessivamente burocratizada, no lugar de agilizar o processo educacional, o engessa e estagna.

Shulman (1987) nos adverte a respeito do cuidado que se deve ter com uma abordagem meramente técnica do ensino, que pode transformá-lo em um empreendimento científico que tenha perdido sua alma.

\section{VALORIZAC̣ÃO DO PROFESSOR}

Tardiff et al (1991) chamam a atenção para a ambiguidade existente em torno do profissional da Educação na sociedade contemporânea, uma vez que este ocupa, simultaneamente, uma posição estratégica e socialmente desvalorizada. Esta ambiguidade é percebida pelos protagonistas desta pesquisa, uma vez que a valorização/desvalorização do professor é, também, um tema recorrente entre os entrevistados. Existem várias circunstâncias em que um profissional pode se sentir alvo de valorização ou desvalorização. Para estes professores, tais questões ganham destaque no que diz respeito à retribuição direta que recebem pelo seu trabalho (salário) e no investimento que é feito em sua formação profissional.

Em suas narrativas pudemos identificar que, de um modo geral, estão conscientes do valor de seu trabalho, reconhecem-se como profissionais competentes e que se empenham por em dar o melhor de si naquilo que fazem. Justamente em função disto, lhes é bastante perceptível a relação de discrepância entre o investimento que promovem para a realização de seu trabalho e o que recebem em troca, tanto no que diz respeito ao sistema público quanto ao sistema privado de ensino, resultando em um sentimento de frustração e revolta. Luís exemplifica bem esta situação: ... a gente ganha pouco, a gente não é reconhecido, a gente trabalha pra caramba...

A estreita relação entre o desenvolvimento da escola e o desenvolvimento docente vem à tona através das falas de nossos entrevistados. A indissociabilidade entre professor e escola é identificada e verbalizada por eles mas, antes de tudo é vivida por cada um desses atores em seu cotidiano de trabalho. 
A fala de Eduardo revela esta compreensão: Na verdade, a escola não percebeu, ainda, que o investimento na formação do professor é investimento na escola.

Esta percepção está em sintonia com o que afirma Linhares (1997, p. 146) ao vislumbrar a possibilidade de uma mudança na compreensão do significado do espaço escolar: "a invenção de uma nova escola não se pode fazer só com professores, mas não se fará sem eles". E a autora acrescenta: "Qualquer esforço de invenção será impossivel de chegar a bom termo, se for feito à revelia dos professores".

Observamos que, a despeito da existência de uma estrutura que imobiliza o professorado em sua caminhada em busca do aperfeiçoamento profissional, rebaixa-o com relação à sua autoestima e isola-o de seus pares, há um movimento que parte dos próprios professores - constatamos, especificamente, em nossos entrevistados - no sentido de apropriar-se da construção de seu próprio desenvolvimento profissional. Encontramos nas palavras de Eduardo uma síntese que expressa essa ação, quase compulsiva, de nossos atores. É justamente em função de tal movimento que encontramos cada um deles no curso ponto de partida de nossa análise: O professor, ele não pode parar de se informar, ele não pode parar esse processo... (Eduardo)

\section{RELAC̣ÃO COM OS PARES}

O contato entre colegas mostrou-se como ponto fundamental para reflexão a respeito do desenvolvimento profissional, na medida em que todos entrevistados descreveram situações de troca com outros professores e atribuíram uma importância significativa a este componente de sua trajetória profissional. Pudemos perceber, a partir de seus depoimentos que, ao se relacionar com um colega, mesmo ao longo de uma conversa informal, é possível constatar a vivência de situações semelhantes, problemas equivalentes e identificar a possibilidade de se explorar outros caminhos na ação profissional. Inicia-se, assim, um processo de reconhecimento de si e do outro e, principalmente, a descoberta da existência de muitos pontos em comum. Marcelo Garcia (1992, p. 70) sugere que "o diálogo entre colegas da mesma profissão contribui para romper o isolamento do professor".

Um exemplo que expressa a presença de intercâmbio de informações entre os professores é que todos os entrevistados tiveram conhecimento do curso em questão a partir do contato com alguém, em geral, colegas que já tinham feito ou que pretendiam participar desse curso. Interessante observar que nenhum deles soube do curso em função de algum meio oficial de divulgação. $\mathrm{O}$ contato interpessoal foi mais eficiente.

Todos os entrevistados apresentam relatos de interação com colegas, no entanto, apresentam graus diversificados de entrosamento com os seus pares, como revela os seguintes exemplos: Renata demonstra a sua "inquietação" ao lidar com situações difíceis, como por exemplo, "com relação àquele grupo de alunos que (...) 
achava que não aprendiam”. Mas, ao buscar respostas nos cursos dos quais tem participado é, principalmente por intermédio das trocas de experiências com outros docentes que tem encontrado caminhos que apontam para as "coisas que funcionam e coisas que não funcionam".

A história de Renata nos conduz à afirmação de Nóvoa (1992, p. 26) de que: "o diálogo entre professores é fundamental para consolidar saberes emergentes da prática profissional" e avaliamos que as vivências relatadas por outros professores, ainda que trabalhassem em outras escolas, foi extremamente importante para que Renata se sentisse respaldada por seus pares e mais segura em seu proceder. Segundo Santaella (1998), a colaboração entre docentes reduz a incerteza, o medo de errar, fomenta o compromisso e o desenvolvimento contínuo e eleva o sentido de eficácia e o êxito entre os professores.

Luís é o exemplo mais marcante, entre os entrevistados, de ter experimentado uma mudança significativa em sua trajetória profissional em decorrência dos incentivos recebidos de colegas da escola municipal.

\footnotetext{
... a equipe de Ciências, também, muito envolvida no trabalho. Fazia reuniões, procurava sempre trocar ideias, trocar experiências. Eu nunca tinha tido isso. (...) Era um estimulando o outro a fazer um trabalho melhor, motivando o outro. (...) eu comecei a ver a Educação com outros olhos (...) comecei a ver que dar aula não era uma coisa tão chata (...) comecei a me interessar, cada vez mais, por Educação.
}

Pelo relato de Júlia, podemos ver que ela é quem alcançou um maior grau de entrosamento e cooperação com relação aos colegas que atuam na mesma escola. Júlia descreve a intencionalidade de se fazer um trabalho conjunto com os professores da área de Ciências e também de outras áreas e que, para isto, muitos deles estão participando juntos de um curso de Pós-Graduação relacionado à Educação Ambiental, com enfoque interdisciplinar. Júlia menciona também as dificuldades enfrentadas na escola resultado de questões da burocracia interna, mas explica que, mesmo não tendo um momento estabelecido oficialmente para discussão na escola, o grupo tenta descobrir formas alternativas de estabelecer comunicação entre si através de contatos telefônicos e encontros rápidos, na hora do recreio.

O que nos chama atenção no relato desta entrevistada é a organização dos próprios professores para desenvolverem um trabalho coletivo ao cursarem, juntos, o curso de Pós-Graduação. Da mesma forma, isto é revelado pela reação da equipe ao deparar-se com a dificuldade de reunir-se oficialmente, criando mecanismos próprios, transgredindo o estabelecido, não se deixando limitar pelos empecilhos impostos pela coordenação pedagógica, rompendo com a burocracia escolar.

Santaella (1998) avalia que o estabelecimento do trabalho colaborativo entre professores, como o descrito na narrativa de Júlia, favorece que a equipe docente tenha a coesão e a organização necessárias para responder de maneira satisfatória às limitações do entorno, criando estratégias para enfrentá-las ou 
mesmo buscar a sua transformação. Esta autora (op. cit.) afirma, ainda, que a cooperação permite aos professores interagir com os sistemas comunitários e políticos com um sentimento de maior confiança de si mesmos.

Visualizamos, então, que o estabelecimento do encontro entre pares pode conduzir o professor a identificar a si próprio como cidadão e a constatar que os problemas enfrentados no cotidiano escolar estão vinculados à confluência de aspectos históricos, políticos, econômicos e culturais extremamente complexos, exigindo dele ao buscar mudança na/da escola, uma ação que vai para além da própria escola, fundindo o seu papel de educador e de cidadão.

\section{CONSIDERAÇÕES FINAIS}

$\mathrm{Na}$ intenção de tecermos algumas considerações finais, queremos reafirmar com base em Santaella (1998), a importância que dispensamos àquilo que os professores dizem a seu respeito. Segundo Nóvoa (1995), a expressão de tais ideias revela um movimento de autoconsciência. Este mesmo autor propõe que o primeiro passo em direção a transformações significativas no agir docente é dado quando o professor tem a possibilidade de refletir sobre suas próprias ideias, sobre sua prática.

Neste sentido, consideramos que o trabalho investigativo aqui descrito, ao mesmo tempo em que serviu-nos para conhecer mais sobre a formação docente, também se configurou como uma estratégia reflexiva que, ao dar voz ao professor, oferecia oportunidade a este para pensar sobre sua trajetória profissional, favorecendo, assim o movimento de autoconsciência.

Acompanhando, mais de perto, este processo, entre nossos entrevistados, observamos que os mesmos têm desenvolvido uma percepção crítica de sua ação, identificando a necessidade de mudanças e reconhecendo a dificuldade destas serem efetivadas. Todos revelaram uma grande avidez por expandir seus conhecimentos e aprimorar sua prática docente, engajando-se em outras atividades de formação continuada após o curso ou paralelamente a este, demonstrando preocupação em investir na carreira profissional. Manifestaram, também, o desejo de divulgar suas vivências e reflexões: participando de encontros, congressos, outras atividades como formadores de formadores.

A presença das características mencionadas acima, associadas ao aumento da autoestima, e ao reconhecimento da própria competência, é considerada por Selles (2000) como um dos indicadores do desenvolvimento profissional docente.

Encerrando este artigo, gostaríamos de lembrar das palavras de Nóvoa (1992, p. 28) ao chamar atenção da indissociabilidade entre o desenvolvimento da escola e o desenvolvimento profissional do professor, enfatizando a necessidade de haver um investimento governamental que abarque, simultaneamente, a formação docente e as instituições de ensino para que ocorra uma transformação qualitativa na Educação: 
As escolas não podem mudar sem um empenhamento dos professores; e estes não podem mudar sem uma transformação das instituições em que trabalham (...) A formação de professores deve ser concebida como uma das componentes da mudança, em conexão estreita com outros setores e áreas de intervenção, e não como uma condição prévia da mudança. A formação não se faz antes da mudança, faz-se durante.

\section{REFERÊNCIAS BIBLIOGRÁFICAS}

CODO, Wanderley; GAZZOTTI, Andréa A. Trabalho e afetividade. In: CODO, W. (org)Educação: carinho e trabalho. Petrópolis, RJ: Vozes/Brasília: CNTE: UNB. Laboratório de Psicologia do Trabalho, 1999.

FONTOURA, Maria Madalena. Fico ou vou-me embora?. In: NÓVOA Antônio (org) Vidas de professores. 2 ed. Porto: Porto Editora, 1995.

HUBERMAN, Michael. O Ciclo de Vida Profissional dos Professores. In: NÓVOA, Antônio (org) Vidas de professores. 2 ed. Porto: Porto Editora, 1995.

LINHARES, Célia F. S. A Escola e Seus Profissionais: tradições e contradições. 2 ed. Rio de Janeiro: Agir, 1997.

MARCELO GARCIA, Carlos. A formação de professores: novas perspectivas baseadas na investigação sobre o pensamento do professor. In: NÓVOA, A. Os Professores e a sua Formação. Lisboa: Publicações Dom Quixote/Instituto de Inovação Educacional, 1992.

NÓVOA, A. Os Professores e a sua Formação. Lisboa: Publicações Dom Quixote/Instituto de Inovação Educacional, 1992. Formação de professores e profissão docente. Vidas de professores. $2^{\text {a }}$ edição. Porto: Porto Editora, 1995.

SANTAELLA, Cristina Moral. Formación para la profesión docente. Madri: Grupo FORCE y Grupo Editorial Universitario, 1998.

SELLES, Sandra L. E. Formação continuada e Desenvolvimento profissional de Professores de Ciências. Ensaio - Pesquisa em Educação em Ciências, Belo Horizonte, v. 2, n. 2, dez 2000.

TARDIF, Maurice, LESSARD, Claude e LAHAYE, Louise Os professores face ao saber. Esboço de uma problemática do saber docente. Teoria e Educaşão, 4, 1991.

Data recebimento: 29/03/2009

Data aprovação: $30 / 07 / 2010$

Data versão final: $09 / 08 / 2010$ 